\title{
Construction of a Bilingual Dictionary Intermediated by a Third Language
}

\author{
Kumiko TANAKA \\ 1)ivision of Fingineering, University of 'Tholyo. \\ 7-3.1 Hongo, Bunkyouku, 'Tokyo, 1.13, Japau. \\ kumiko@ipl,f, u-tokyo.ac.jp
}

\begin{abstract}
When using a thied language to constrnct a bilingual dictionary, it is necessary to discriminalo equivalencies from inappropriate words deriver as a result; of ambigutity in the thind language. We propose a method to treat this by ntilizing the structires of dictionaries to measure the nearness of the meanings of words. 'Lhe resulting riclionary is a word-to-word bilingual dictionary of nouns and can be used to refine the entries and equivalencies in published bilingual dictionaties.
\end{abstract}

\section{Introduction}

When vocabulary camnot be found in bilingual dictionaries, it is frequently obtatued by using a third language as an intermediay. 'l'his indicates that supplemental information may lic in other forms in other dictionaries. Ilere we try nsing electronic dictionaries which cat be reformed on a large scale, to extract this informations so that we can obtain subsidiary datia and refine a rlinect. bilingual dictionary.

Looking: uy words in bilingual dictionaries in termediating the third language is a method often used by people who handle uncommon languages in a specific domain. If this process can be anto. mated, bilingual dictionaries of any kind between any languages nay be obtained as long as these concerned languages have dictionaries to a comtmon language. One objective of the research re ported here is to establish a first step in antematting this process.

To construct a Japaneset $\rightarrow$ Trench dictionary, we chose Finglish as the intermediary language because Japanese $\rightarrow$ Winglish and Finglish $\leftrightarrow$ French dictionaries exist in electronic forms and because published Japaneser rench dictionaries provide enough vocalulary in comparison with the resulting dictionary.

In Section 2 we describe a method for extracting equivalencies for a given word. Its fundancm. tal conceptsi are stated in Section 3. The: whole: procedure used to construct the new dictionary is shown in Section 4 and in Section 5 the resulting dictionary is evaluated.

Japanese-Fnglish, Fuglish-Japanese, PuglistFrench, French-Bnglish, Japanese-french and French-Japanese dictionaries are respectively de-

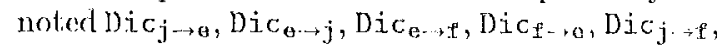

\section{Kyoji UMMIMURA}

NTT Basic Research Taboratorius. 3-9-11 Midori, Musashino, 'Pokyo, 180, Jatran. unemuradnesun . NT"厂 . JP

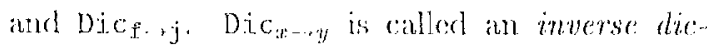
tionary of Dic $y, \ldots$. Japanesese words late information in the following format: pronmonciation in romaji, and its exprivalence in longlish. Hnglish words are writiten in this font and french words in this font.

\section{Overview of the Method}

\subsection{Tnverse Comsultation}

the most naive way to nse Finglish to oldain French words comesponding to a Japhanese word is to look nep the Japanese word in a Dicj-., and then look up the monttant Enplish words in a Dice-t. The resulting Fuchel words can be regarded as equivalence candidaties (F,Cs) of the original Japanese wort. For oxamplo, in Fig. 1,

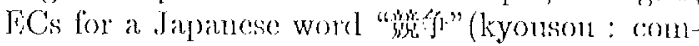
petition) are competition, concours, race etc. Anomg these, race and hate are inaclecputite as

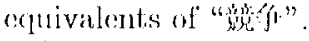

As for race, the linglish worel race lats several meanings with the same spelling: one is 10 compete and another is human race. It is human race which induces the inadequate for race. As for hate, the linglish word race has the wider mean. ing to hurry which the original Japanese word “䋹 fo." does not. Since hate is a direct tomslation of to hurry, it is inappropriatio ats an equivalence.

the following three asses genemate irrelevant pCs.

1. An linglish word with the same spelling but with dillerent memings is internedialeel. (aree in the aloove example)

2. An English word with a wider meaning than that of original Japanese word is intermesli. ated. (hate in the above example)

3. There are mistakes in dietionaries.

The first two cases are clue to the ambignity in English. An English word with a narrower meaning than the bafanese source maty miss some loneh equivalents. We think that if the orighinal worel has antrignity and several monnings, the dictionary gives the corresponding dinglish words.

We could liandle the problem of choosing e puivalencies from anong lics by semantic processing, but expressing meaning of vocabulary in diclionaries is a great problem. A simpler way is lo look the lics up in the inverse dictionary. For example, one can consult Dic $c_{-\ldots j}$ for compétition,

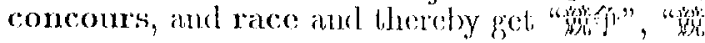




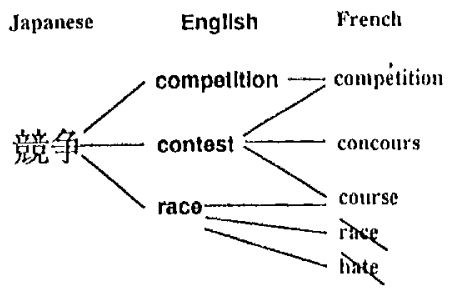

Fig. 1 Equivalence candidates (ECs) for “敨争”.

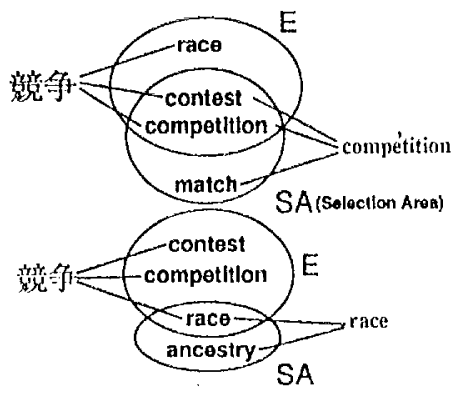

Fig. 2 One time inverse consultation $\left(I C_{1}\right)$.

争", and “人種" (jinshu : human race) as their respective equivalencies. Since "人程" has notl $l_{-}$ ing to do with "端行" , race is excluded. We call this method of looking up ECs in the inverse dictionaries when choosing relevant equivalencies inverse consultation, and we call the words obtained by looking up inverse dictionaries the selection area (SA). Inverse consultation utilizes the structure of dictionaries to measure the nearnoss of the meanings of words in different languages.

The simplest application of inverse consultation is to use Dic $\mathrm{f}_{\mathrm{f} \rightarrow \theta}$. In the above example, each EC is looked up in DiC $\mathrm{f} \rightarrow \mathrm{e}_{\mathrm{e}}$ and the results are compared with the English equivalencies of "竌fl." (E); namely, competition, contest, and race. The SA of competition is competition, contest and match, which have the elements contest and competition in common with $\mathrm{E}$ (Fig. 2). As compétition derived from competition, competition should be put aside, but contest is still left as a common element and thus competition is selected as an

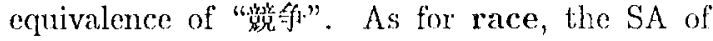
race consists of race and ancestry, whose intersection with $\mathrm{F}$ only gives race; so race is jurlged as an inaclequate EC. In short, the number of elements in common between the selection asea and $E$ indicates the nearness of the meaning between the EC and the original word.

For the inverse consultation described above, the SA was in English. If we use $D i c_{e \rightarrow j}$ as an inverse dictionary successively after consulting $D i c_{f \rightarrow e}$, then the $S A$ is in Japanese and we compare "数尔" with the SA (Fig. 3). The SA for

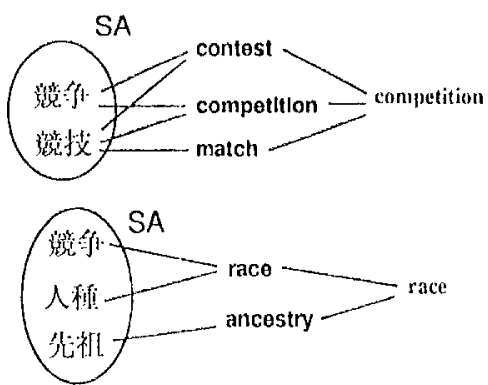

Fig. 3 Two times inverse consultation $\left(I C_{2}\right)$.

compétition consists of two "新 fr." $\mathrm{s}$ and three "蜶技"s (kyougi : game). For race, the SA has

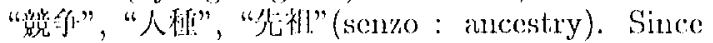
"新 for" appear's only once for race, we riscard the $\mathrm{EC}$ race.

There can be a infinite number of inverse consultations according to the number of consulted inverse dictionaries. If the inverse dictionaries are consulted $n$ times, we call the method $n$ times inverse consullation $\left(I C_{n}\right)$. Which inverse dictionary to use does not always have a unicue answer. For $I C_{2}$ for example, we may consult Dic $c_{e \rightarrow f}$ after consulting Dic $\rightarrow$ e with the SA in French.

\subsection{Selection Procedure}

Once the $\mathrm{S} \Lambda$ for a given word is obtained, equivalencies are selected by handling two collections of words. We call this process the selection procedure.

One way to do this is to count the number of specific elements in the SA. For example, if the $\mathrm{S} \Lambda$ is in Japanese, the mumber of the element " fo." itself is comted. Another way is to comt how many parts of words (PWs) are contained in the

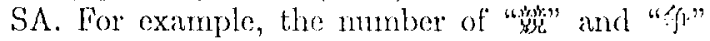
contanined in the SA is considered (thons "with" in "䍌技” is also comnled).

If we handle the meaning of words, a third way is to look up "糈尔." in a Japanese thesaurus and count how many times the synonyms appear in the SA. For example, if "㩆技" is a synonym of"

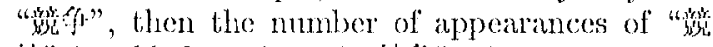
技" is added to that of "孜efr.". If we go furtlier to handle the meaning, we might as well process words by semantic processing.

Since a kanji is an jeleogram, the second method also handles the meaning. When the selection area is in English or French, the corresponding method is to count morphemes such as "inler" and "national" for the word "international". We are interested in to what extent the method that, does not explicitly concern the meaning may be used to handle the meaning of words. In the following, we focus on the former two methods. 


\section{Fundamental Concepts}

3.1. Harmonized Dictionary

A bilingual dictionary forms a graph whose nodes are words and whose branches are correspondences between the words. Branches have directions, which make the graph asymmetric. Dic $\mathrm{c}_{x+4}^{-1}$ is a graph with all the branches in Di $c_{x \ldots y}$ in inverse direction.

Since the purpose of bilingual dictionaries is to denote, the correspondences of words that have the same meaning [Har83], it is natural that branches are bidirectional. We therefore clesign symmetrical dictionaries and wo denote a dictionary from language $x$ to $y$ as $\mathrm{D}_{x-1, y}$, calling it it harmonized dictionary. When $\mathrm{D}_{x-\cdots y}$ and $\mathrm{D}_{y-r, x}$ are constructed from the same dictionaries, $\mathrm{D}_{y \rightarrow x}=$ $\mathrm{D}_{x \rightarrow y}^{-1}$ holds. Wo remove the overlaps of branches.

\subsection{Syntactic Selection Procedure}

A multiset here is a set in which each element has a weight that is a natural number. 'The weight of an element is defined as the number of times it appears when looking up words in dictionaries. In the example shown in Fig. 3, the multiset $\mathrm{SA}$

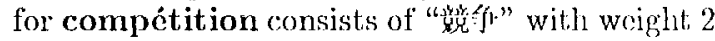
and "㜔技" with weight 3 . We denote the weight of element $x$ in multiset $X$ as $\delta_{\mathrm{a}}(X, x)$; for instance, $\delta_{\mathrm{a}}(S A$, 䊁称 $)=2$. Using the sime notation, $\delta_{\mathrm{a}}(X, Y)$ is defined as follows when $X$ and $Y$ are multiscts:

$$
\delta_{\mathrm{a}}(X, Y)=\sum_{y \in Y} \delta_{\mathrm{a}}(X, y)
$$

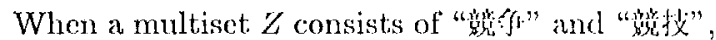
then $\delta_{\mathrm{a}}(S A, Z)=5$.

The notation $\delta_{\mathrm{b}}(X, x)$ represents the sum of the weights of the elements that contain PWs of $x$ in multiset $X$. For instance, if PWs are defined as kanji, $\delta_{b}(S A$, 敨新) is 7 by adkling 5 (sum of weights of elements in the SA that, have kanji "袮") and 2 (sum of weights of elenents in the SA that have kanji "Sf."). Using the same notation, $\delta_{\mathbf{a}}(X, Y)$ is definexl as follows when $X$ and $Y$ are multisets:

$$
\delta_{\mathrm{b}}(X, Y)=\sum_{y \in Y} \delta_{\mathrm{b}}(X, y)
$$

For instance, $\delta_{\mathrm{b}}(S A, Z)=12$; that is 7 phis 5 $\left(=\delta_{\mathrm{b}}(S A\right.$, 帨技 $\left.)\right)$. We use the notation $\delta$ as a parameter for $\delta_{\mathrm{a}}$ or $\delta_{\mathrm{b}}$.

\subsection{Properties of Inverse Consultation}

In the following, we use $D_{f \rightarrow \theta}$ and $D_{e \rightarrow j}$ as inverse dictionaries when starting from Japaneses words and we use $D_{j \rightarrow e}$ and $D_{0 \rightarrow f}$ as inverse dictinnaries when starting from French words. French DCs for a Japanese word $\mathrm{j}$ form a multiset $\mathrm{F}$ expressed as $F=D_{e \rightarrow+P} D_{j \rightarrow 0} j$.

French equivalencies selected by $I C_{1}$ form $n$

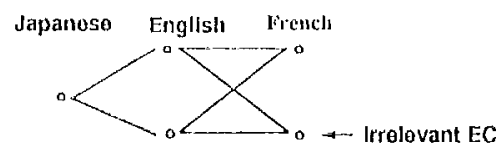

Fig. $4 \Lambda$ structure that $\delta_{n}$ is inapplicalole.

multiset whose element $f$ satisfies

$f \in F$ and $\delta\left(D_{f \rightarrow 0} f, D_{j \rightarrow e} j\right)>1$.

French equivalencies selectod by $I C_{2}$ form a mul tiset whose element $f$ satisfies

$f \in F$ and $\delta\left(D_{e \rightarrow \vdash j} D_{f \rightarrow e} f, j\right)>1$.

In the following, we focms on the $I C_{1}$ and $I C_{2}$ described above and examine thoir properties.

Property 1

$$
\begin{aligned}
\delta_{\mathrm{a}}\left(\mathrm{D}_{\mathrm{e} \rightarrow \mathrm{j}} \mathrm{D}_{\mathrm{f} \rightarrow \mathrm{e}} \mathrm{f}, \mathrm{j}\right) & =\delta_{\mathrm{a}}\left(\mathrm{D}_{\mathrm{j} \rightarrow \mathrm{e}} \mathrm{j}, \mathrm{D}_{\mathrm{f} \rightarrow \mathrm{e}} \mathrm{f}\right) \\
& =\delta_{\mathrm{a}}\left(\mathrm{D}_{\mathrm{e} \rightarrow \mathfrak{f}} \mathrm{D}_{\mathbf{j} \rightarrow \mathrm{e}} \mathrm{j}, \mathrm{f}\right)
\end{aligned}
$$

This property indicates that whon lusing solection procedure $\delta_{a}$, ecpuivalencies selected by $l C_{1}$ and IC.2 are exactly the same. Moreover, it is sulficient to choose BCs whose weights are greater than 1 in F. 'Fhe proof of Property 1 is shown in Appendix.

Property 2 If $\delta$ is $\delta_{a}$, the resulting Japanesewench dictionary is a harmonized dictionary. This is not always true for $\delta_{1}$.

'Jhis property is clear with symmetrically structured dictionaries. When $\delta_{b}$ is used, the resulting dictionary depends on how PW is defined and does not always become a harmonized dictionary.

Property 3 If there is a structure such as shown in Fig. 4, $\delta_{\mathrm{b}}$ must be used as $\delta$ to exclude: irrelcyant BCs.

When $\delta_{\mathrm{a}}$ is used, the $\mathrm{S} A$ for two teds will be exactly the sane, which makes it impossible to cliscard inappropriate bCs. Althongh this kind of structure seents to be rare, it can exist because of the historical transition of words. When a single

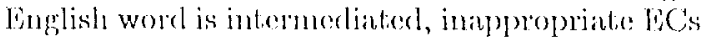
cannot be discarded by using $\delta_{a}$ for $I C_{1}$.

\section{Tixperiment:}

\subsection{Dictionary Data}

'The diclionaries nsed in the experiment, are $\mathrm{DiC}_{\mathrm{j} \rightarrow \mathrm{e}}[\mathrm{Ich} 90)$ ], Dic $\mathrm{c}_{\mathrm{e} \rightarrow \mathrm{j}}$ [Koi90], Dic $\mathrm{C}_{\mathrm{e} \rightarrow \mathrm{f}}$ [For82], and Dicf $\rightarrow$ [Led82]. 'The whole experimental procedure is shown in Jig. 5. Worl-to-word dictionaries are first extaneted from each dictionary. All words are nouns; in particular, they are one word nouns in linglist and french. Since the dictio. nary syntax was not; always consistent, worl-toword dictionaries contain some mistakes (inarle(quate correspondencess).

IIarmonized diclionaries are then constructed from the word-to-word dictionaries as follows:

$$
D_{a \rightarrow j}=D i c_{j \rightarrow e}^{\cdots 1} \cup D i c_{e \rightarrow+j}
$$




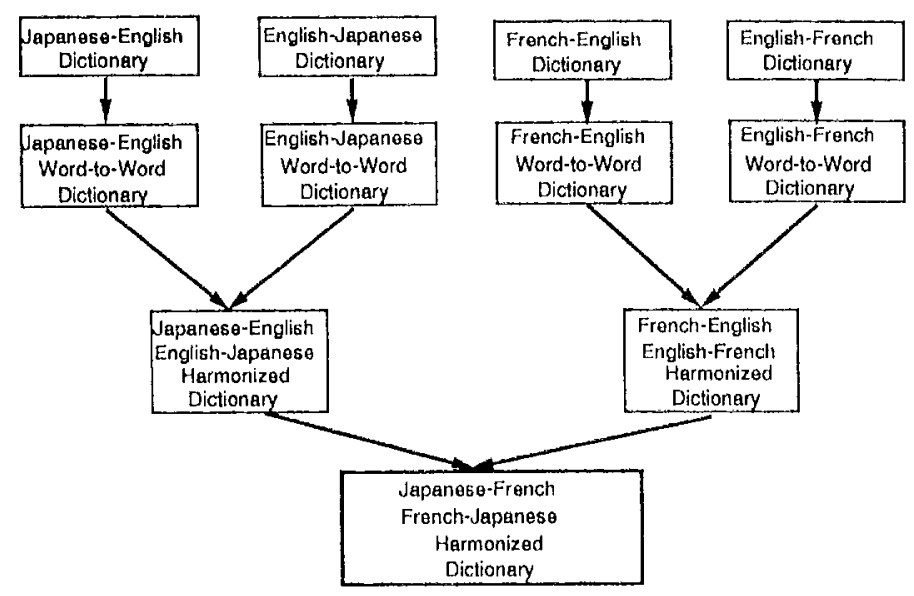

Fig. 5 Whole procedure.

$$
\begin{aligned}
& D_{j \rightarrow 0}=D_{e \rightarrow j}^{-1} \\
& D_{\mathrm{e} \rightarrow \mathrm{f}}=\mathrm{Dic}_{\mathrm{f} \rightarrow \mathrm{e}}^{-1} U \mathrm{Dic} \mathrm{a} \rightarrow \mathrm{f} \\
& D_{f \rightarrow e}=D_{e \rightarrow f}^{-1}
\end{aligned}
$$

Although there are other ways to symmetrize dictionaries, (for example, by removing all branches that are not bidirectional), we chose the above procedures for the lexicographical roason doscribed below [IIar83].

There are two kinds of bilingual dictionaries, one is from a foreign language $(f)$ to the mother language (Dic $f \rightarrow m$ ), and the other is from a mother language $(m)$ to a foreign language $\left(\right.$ Dic $\left._{m \rightarrow-f}\right)$. In Dic $f \rightarrow m$, when there are no equivalencies in $m$ for a foreign word, the dictionary gives its definition or explanation of the word in $m$. Therefore, all the foreign words can be contained in the dictionary. In Dic ${ }_{m \rightarrow f}$ on the other hand, if there are no equivalencies in $f$ for a word of $m$, the word itself is often dropped from the dictionary. The words contained in the dictionary are therefore a part of $m$, and Di $c_{m \rightarrow f}$ lacks many entries. A harmonized dictionary is a solution tio this problem because it contains equivalencies of Dic $_{f \rightarrow m}$ as centries of Dic Dis $_{m \rightarrow f}$.

\subsection{Procedure of Inverse Consultation} From Property 1 , we use $\delta_{\mathrm{a}}$ with $I C_{1}$ and we use $\delta_{\mathrm{b}}$ with $I C_{2}$. The $\mathrm{PW}$ for $\delta_{\mathrm{b}}$ are defined as follows:

- Japanese 6353 kanjis.

- French morphemes [Mau85]. 1151 prefix and 710 suffix.

From Property 2, inverse consultation is applied to both Japanese and French entries, and then the results are put together to construct a harmonized dictionary. We denote it as $D_{j \rightarrow f}$ or $D_{f \rightarrow j}$.

Fach entry within $D_{j \rightarrow e}$ and $D_{f \rightarrow 0}$ is chassified into one of five types according to the procedure used to select its equivalencies from ECs.
- 'Iype $\Lambda$ A single EC exists and is selected unconditionally as the equivalence.

- 'Iype, B Equivalencies by $I C_{1}$ exist; all are selected and the rest of the ECs are discarded.

- Type C There are no equivalencies by $I C_{1}$ but there are by $I C$. . One third (empirically decided) of $\mathrm{ECs}$ by $\mathrm{I}_{2}$ are selected according to the value of the following fraction (langer ones are selected):

$$
\frac{\text { Value of finction } \delta_{\mathrm{b}}}{\mathrm{SA}(\text { byte) }}
$$

- Type D No equivalencies by $I C_{1}$ nor by $I C_{2}$ appeared but there are several ECs. For this entry, it is impossible to select the relevant equivalencies.

- Type E There are no ECs.

Entries of Type $A$ accuire more appropriate equivalencies than do entries of Type $B$, and entries of Type B acquire more appropriate cquivalencies than do entries of 'Type C.

\section{Evaluation of Experiment}

\subsection{Result of the Fxample}

Equivalencies obtained for the Japanese word "wos ar." are

concours, rivalité, compètition, course, concurrence, émulation

and the intermediated English words are competition, contest, rival, rivalry, race.

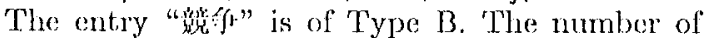
ECs is 41 (including overlaps), and 13 of them are selected by $I C_{1}$. The number of ECs in each category of irrelevant words described in Section 2.1 is listed in Table 1, which indicates that, inverse consultation can detect the relevant, words even when there are mistakes in the dictionaries. The word which should not be dropped was joute.

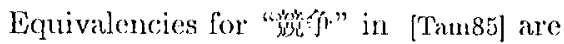


Table 1 Details of FCs of "kst

\begin{tabular}{|l|r|}
\hline Selected equivalencies & 13 \\
Different meaning in English & 9 \\
Mearing extended in Fnglish & 9 \\
Mistakes of dictionaries & 9 \\
Words which nutst not be dropyed & 1 \\
\hline
\end{tabular}

Table 2 Classification of entries.

\begin{tabular}{|l|rr|rr|}
\hline & \multicolumn{2}{|c|}{$\mathrm{D}_{\mathrm{j}-\mathrm{f}}$} & \multicolumn{2}{c|}{$\mathrm{D}_{\mathrm{f}, \mathrm{j}}$} \\
\hline T'otal & 42100 & $(100.0 \%)$ & 23710 & $(100.0 \%)$ \\
Type A & 1600 & $(3.8 \%)$ & $385 \%$ & $(16.2 \%)$ \\
Type B & 8179 & $(19.4 \%)$ & 7397 & $(31.3 \%)$ \\
Type C & 24047 & $(57.0 \%)$ & 0452 & $(27.2 \%)$ \\
Type D & 1514 & $(3.6 \%)$ & 2988 & $(12.6 \%)$ \\
Type E & 6850 & $(16.2 \%)$ & 3021 & $(12.7 \%)$ \\
\hline
\end{tabular}

Table 3 Fntries with no $\mathrm{liC}$.

\begin{tabular}{|c|c|c|}
\hline rategory & example & $\begin{array}{l}\text { Enylish } \\
\text { canivalence }\end{array}$ \\
\hline Cultural words & $\begin{array}{l}\text { Jj } 1 \text { : } 1 \text { (otoshidanta : } \\
\text { Onr tradition to give } \\
\text { money to children on } \\
\text { New Year) } \\
\text { cédille: }\end{array}$ & cedilla \\
\hline $\begin{array}{l}\text { Teclinical terms } \\
\text { or proper nouns }\end{array}$ & $\begin{array}{l}\left.7 x^{2}\right) \times \text { (gants: gausss) } \\
\text { Cicéron }\end{array}$ & $\begin{array}{l}\text { gauss } \\
\text { Cicero }\end{array}$ \\
\hline Borrowed worels & 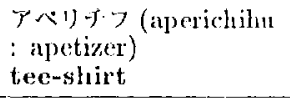 & $\begin{array}{l}\text { apéritif } \\
\text { teeshirt }\end{array}$ \\
\hline
\end{tabular}

concours, rivalité, compètition, course, concurrence.

On result contains emulation (which means ri$v a l r y)$ in addition to the entries in the published dictionary.

\subsection{Evaluation of Entries}

Table 2 lists the oach number of entries belong: ing to the Types $\Lambda \sim D$ (deffined in Section 4.2). 'Type J) consists of the following entries.

- One English word is intermediated and sev eral ECs appoar.

- 'The entry contains no PW.

The 'Type D percentage difference between $D_{j \rightarrow f}$ and $D_{f \rightarrow j}$ shows that the number of entries of Type D depends on tite number of registered PWs.

No EC appears when an Buglish word to be intermediated does not exist as the entry of $\mathrm{D}_{\mathrm{e}-\mathrm{i}} \mathrm{f}$ or $\mathrm{D}_{\mathrm{a} \rightarrow \mathrm{j}}$. Such entries can be calegorized as in Table: 3

Original words are apt to be translated into nucommon binglish words, so they normally do not appear as entries if the same kind of worels do not: exist; in the objective langange. 'Jechnical tewns and proper nouns depend very much on culture. 'lable 4 fivaluation of equivalencies.

\begin{tabular}{|c|r|r|r|r|}
\hline & \multicolumn{2}{|c|}{$\mathrm{D}_{\mathrm{j}}, \mathrm{f}$} & \multicolumn{2}{|c|}{$\mathrm{D}_{\mathrm{f}-\mathrm{j}}$} \\
\hline rate & $\mathrm{R} 1$ & $\mathrm{K2}$ & $\mathrm{R} 1$ & \multicolumn{1}{c|}{$\mathrm{R2}$} \\
\hline $80 \% \sim 100 \%$ & 58 & 56 & 18 & 58 \\
$60 \% \sim 80 \%$ & 4 & 1.1 & 8 & 1.5 \\
$10 \% \sim 60 \%$ & 9 & 13 & 13 & 9 \\
$20 \% \sim 40 \%$ & 8 & 10 & 24 & 1 \\
$0 \% \sim 20 \%$ & 22 & 7 & 37 & 14 \\
\hline
\end{tabular}

Matyy Fonch placenanes, for instance, are 'Typo fi. Borrowed worls ate expessed in inconsistent. spellings, and which ol them are to be fonnt in the diclionary also rlepends on the culture (apéritif is: the equivalence in Dic $\mathrm{j}_{\mathrm{-}, \mathrm{e}}$ ).

Since a harmonizing dirtionary angunents the entrics, the resulting alictionary contabins entries that are not in the publisher elictionary. As explained in Section 4.1, this phenomenon is contspicnoms when wo compare $D_{j \rightarrow f}$ with the published rlictionaty [Suz70]. 'J'hose entries cau be cat.egorized as lollows:

1. Collocpuial worrls. lix. われたやん (wanchan : puppy)

2. Technical terms on proper nomm. Fx. アメバスト (asubesuto : asbosto)

3. Componurl moluts.

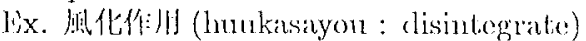

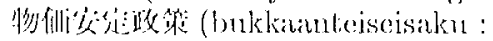
valorization)

Irarmonizing dictionaries help to gather correspondences between the mother language and a foroign language and are nsefil in revising published dictionarios.

\subsection{Evaluation of Equivalencies}

We cvaluated the equivalencies of resulting dictionaries ly comparing lhen with those of published dictionaries ['1'an85] [Suzo)]. For rantom 100 entries in both dictionaries, the following two percentages (calculaterl manulally) alde listed in Tablo I:

- RI Faction of ecpuivalencies in the published dictionary which were also found by this method.

- R2 Faction of ecpuvalencies foutud by this method which were judged appropriale.

Note that entries with greater R2 contain appro. priate equivaleneies on higher rate. This is uot true for $R 1$, since $R 1$ indicates the discrepancy of equivalencies betweon the resulting dictionary and published dictionarios.

Entries of $182=100 \%$ can be classified as follows:

1. Entries of 'Lype $A$ or 1 . (See Section 4.2.)

2. Entries that have less than thres bCs.

Fintries with less than 3 TCs anount to $29.0 \%$ for $D_{j \rightarrow f}$ and $34.2 \%$ for $D_{f \ldots, j}$. This indicates $\left.t\right]_{1 a t}$ words with specific meanings are apt, to acepure appropriate epuivalencies. 
Table 5 French entries whose $\mathrm{Rl}$ are $0 \%$

\begin{tabular}{|c|c|c|}
\hline entry & $D_{f \rightarrow j}$ & $\begin{array}{l}\text { Published dictionary } \\
\text { [Tam85] }\end{array}$ \\
\hline distique & $\begin{array}{l}\text { 你 速 们, 対 们 (gy- } \\
\text { ourenku, tuiku : } \\
\text { the terminology for } \\
\text { Japanese and Chi- } \\
\text { nese poems of same } \\
\text { kind) }\end{array}$ & $\begin{array}{l}2 \text { 行 } \text { th }^{2} \text { gyou-slit : } \\
\text { coinage for the term } \\
\text { for European poems) }\end{array}$ \\
\hline pull & $\begin{array}{l}\text { t- y- ( sectaa } \\
\text { : sweater written } \\
\text { with Japanese let- } \\
\text { ters. This word is } \\
\text { common) }\end{array}$ & 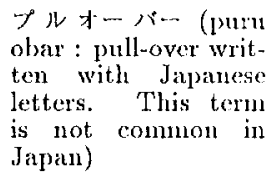 \\
\hline boulier & $\begin{array}{l}\text { sy (sanbau : Aba- } \\
\text { cus in general) }\end{array}$ & 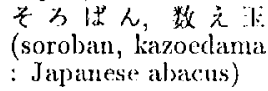 \\
\hline
\end{tabular}

Table 6 Japanese entries whose $\mathrm{R} 1$ are $0 \%$.

\begin{tabular}{|c|c|c|}
\hline entry & $\mathrm{D}_{\mathbf{j} \rightarrow \mathrm{f}}$ & $\begin{array}{l}\text { Publislued dic- } \\
\text { tionary [Suz } 70\end{array}$ \\
\hline 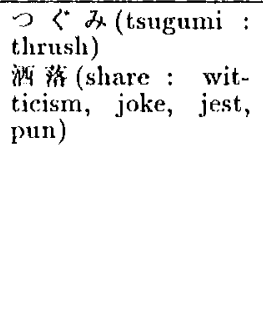 & $\begin{array}{l}\text { grive } \\
\text { astuce } \\
\text { badinage } \\
\text { drôlerie } \\
\text { facérie } \\
\text { farce } \\
\text { plaisanterie }\end{array}$ & $\begin{array}{l}\text { merle } \\
\text { calembour }\end{array}$ \\
\hline
\end{tabular}

The entries tend to have either R1=80\% 100\% or $\mathrm{R} 1=0 \% \sim 20 \%$. Of the latter, some examples are listed in Table 5 and 6 . For distique in Table 5 , which is a term in French literature, $D_{f \rightarrow j}$ translates it into the term for the corresponding kind of Japanese literature. Although it resembles to the direct translation of distique, it is only an analogy. On the other hand, since the direct translation of distique in the published dictionary adopts the concept of French poens, it; is uncommon and cannot be understood by nost Japanese readers. The same is true for boulier except that the common Japanese is indicated in a published dictionary. Pull is borrowed from the English word pull-over whose direct translation is contained in a published dictionary, and it is not: a common word in Japanese.

In the first example in Table 6 , grive is the generic name equivalent to thrush, whereas merle is a kind of thrush. The second example shows that more equivalencies are found in $D_{j \rightarrow f}$.

To sum up, the resulting dictionary can be utilized in conjunction with the published dictionalies as follows:

- To revise the equivalencies.

- To supplement the equivalencies.

Sections of the resulting dictionaries is listed in Table 7. List 1 is $D_{j \rightarrow f}$ and List 2 is $D_{f \rightarrow j}$.
For each list, entries are in the first row and their: equivalencies are in the third row. Symbols in the second row indicate how appropriate each equivalence is. (Refer to the notes beside.)

\section{Related Work}

The use of a third language Fnglish as an intermediary in the construction of a bilingual dictio. nary was tested manually on a large scale on editing the Spanish-Japanese dictionary [Kuw90]. Tt is now a representative middle-sized dictionary latving a large quantity of information.

Tokunaga and Tanaka [Tok90] tried to extract a conceptual dictionary from Japanese-English and English-Japanese dictionaries. Although they used a concept similar to ours that is the graph structure of a dictionary related to mouning of words, their frameworks and final product differ from ours.

\section{Conclusion and Future Works}

The proposed method for using a intermediate language to construct a bilingual dictionary utilizes the structure of dictionaries and morphemes and can choose appropriate equivalencies for most entries. Comparing the resulting dictionary with published dictionaries showed that data obtained are useful for revising and supplementing the vocabulary of existing dictionaires.

To increase the accuracy with which equivalencies can be selected, mistakes in word-to-word dictionaries must be corrected even if our method may detect appropriate equivalencies. One way to do this would be to use thesaurus to check whether the extracted correspondences are relevant.

Nouns were taken into consideration in this research, and the next step will be to apply the proposed method to other parts of speech. We also need to establish a way to handle componnd words in European languages.

Acknowledgements

We express our gratitude to Prof. Hideya Iwasaki of University of 'lokyo for his gruidanee on theoretical aspects and essential remarks on experiments. We are also thankful to Prof'. Nigel Ward of University of Tokyo for his lexicographlical advice and for his invaluable aid in shaping our idea.

\section{References}

[Bog89] Boguraev, B. ct al. (1989). Computational Lexicography for Natural Language Processing. Longman.

[Fil85] Fillmore, C. (1985). Frames and the semantics of muderstanding. Quaderni di Semantica, Vol.o, No.2.

[Fil92] Fillmore, C. and Atkins, B. (1992). Toward a Fame-Based Lexicon. The semanties of RISK and its Neighbors. Acudenic Press. 
Table 7 A part of resulting Japanese $\rightarrow$ French dictionary.

\begin{tabular}{|c|c|c|}
\hline \multicolumn{3}{|c|}{ List 1} \\
\hline \multirow[t]{3}{*}{ bらk啃 } & $0^{*}$ & chatmme \\
\hline & 2 & criniere \\
\hline & 2 & tifs \\
\hline \multirow[t]{2}{*}{ わる } & 1 & ganinerie \\
\hline & $0^{*}$ & malice \\
\hline \multirow[t]{3}{*}{ わんちャん! } & 0 & chien-chien \\
\hline & 0 & chicnehien \\
\hline & 0 & toutou \\
\hline \multirow[t]{3}{*}{ わんわん } & 0 & dhien-chien \\
\hline & 0 & chienchien \\
\hline & $0^{*}$ & toutou \\
\hline \multirow[t]{3}{*}{$9-9$} & 0 & arc \\
\hline & 0 & arche \\
\hline & 0 & voute \\
\hline \multirow[t]{2}{*}{$17-1$} & 0 & ant \\
\hline & 2 & japonisant \\
\hline ! $y^{\prime}$ & () & arbonsier \\
\hline \multirow[t]{7}{*}{$! r-A n ッ ⿻$} & 1 & coucte \\
\hline & 0 & enclenchene?t \\
\hline & () & fermeture \\
\hline & () & inmobilisation \\
\hline & 1 & platine \\
\hline & 0 & sorrutre \\
\hline & 0 & trapillon \\
\hline \multirow[t]{2}{*}{ Yー佂ンド } & ()$^{*}$ & amatids: \\
\hline & 1 & dragée \\
\hline 䐜准元 & $\begin{array}{l}0^{*} \\
0\end{array}$ & $\begin{array}{l}\text { ponnoteny } \\
\text { fondatemi }\end{array}$ \\
\hline \multirow[t]{4}{*}{ 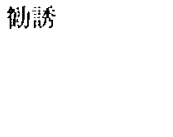 } & 1 & discussion \\
\hline & 0 & invite \\
\hline & 1 & pointage \\
\hline & $\begin{array}{l}0^{*} \\
2\end{array}$ & sollicitation \\
\hline \multirow[t]{3}{*}{ 资人 } & 1 & ruban-cache \\
\hline & 2 & centinctre \\
\hline & 2 & magnétophone? \\
\hline \multirow{3}{*}{$\begin{array}{l}\text { !炎き㴡天 } \\
\text { ! 炎き物 }\end{array}$} & 2 & existence \\
\hline & 0 & rouleau \\
\hline & 0 & volute \\
\hline
\end{tabular}

\begin{tabular}{|c|c|c|}
\hline \multicolumn{3}{|c|}{ List2 } \\
\hline Tanbise & $0^{*}$ & ザンド \\
\hline Zailie & $0^{*}$ & ザイーール \\
\hline Zintbabwe & $0^{*}$ & ジンバナ゙リ \\
\hline !'Joroastre" & () & 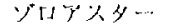 \\
\hline aluaissement & () & 引劫卜け \\
\hline & 0 & $F$ \\
\hline & 0 & 占降 \\
\hline & 0 & 下消 \\
\hline & 0 & 放衫 \\
\hline & $0^{*}$ & 豩少 \\
\hline & 0 & abjls \\
\hline & () & 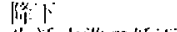 \\
\hline & 0 & 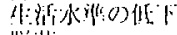 \\
\hline & 0 & 脱济 \\
\hline & 0 & 沈 \\
\hline & 0 & 篗湾 \\
\hline & ()$^{*}$ & II: 1 \\
\hline & () & 被卜 \\
\hline & 1 & 学卜讪湖 \\
\hline & 1 & 济施: \\
\hline & 1 & 细保浮卜 \\
\hline abandonnement & $0^{*}$ & 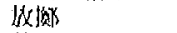 \\
\hline & () & 洏好 \\
\hline abandon & $0^{*}$ & 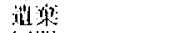 \\
\hline & 0 & Itithl] \\
\hline & 0 & 情滀 \\
\hline & 0 & 衿慢 \\
\hline & 0 & $j \sqrt{1}$ \\
\hline & 0 & Jls sink \\
\hline & 0 & (1) \\
\hline & 0 & 话 \\
\hline & $0^{*}$ & Lat \\
\hline abaque: & 0 & 少 \\
\hline & 0 & $|\cdots|$ \\
\hline & 0 & 国试 \\
\hline & 0 & 测流 \\
\hline & 0 & 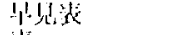 \\
\hline & 0 & 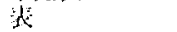 \\
\hline
\end{tabular}

0: Juclged appropriate (counted for R2).

1: Significance slightly different.

2: Significance completely diflerent.

*: Fomud common in lwo dictionaries (cominted for R1).

Mark "!" attached to entries means that the entries were not fonnd in the published dictionitries.

[For82] Forbes, P. et al. (1982). Shorter FnglishFrench Dictionary. Harrap Lindited.

[Har83] Hartmann, R. (1983). Lexicogruphy: principles and practice. Acadenic P'ress.

[Ich90] Ichikawa, S. (1990). Ne'te JapeneseEnglish Dictionary. Kenkyuusha.

[Ide93] Ide, N. and Véronis, J. (1993). Extracting; knowledge basis from machine readable dictionaries. $K B Q K S, J I P D E C$.

[Koi90] Koine, Y. (1990). New English-Japanese. Dictionary. Kenkyumsha.

[Kuw90] Kuwana, K. (1990). Spanish-Japenese Dictionary. Shougakukan.

[Led82] Ledésert, M. et al. (1982). Shorter. French-Lnglish Dictionary. Harrap Limited.

[Mau85] Maubourguet, P. et al. (1985). Crond Dictionnaire Encyclopédique LAROUSSH. Larousse.

[Mil90] Miller, G. et al. (1990). Five Papers on WordNet. CSL Report 4\%. Cognitive Science Laboratory, Princeton University.

[Oht78] Ohtsuki, T. et al. (1978). Crown HirenchJapanese Dictionary. Sanseido.

[Suz70] Suzuki, S. (1970). Standard JapaneseFrench Dictionary. Iaishunkau.

[Tam85] Tamura, T. (1985). Dictionnaire FroncetsJaponais ROYAL. IIakusuisha.
[Tok90] Tokmaga, T'. and Timaka, II. (1990). The Automatic Fixtraction of Conceptinal Itens from Bilingnal Dictionaries. PRICAI.

\section{Appendix}

The following two lemmas are neoded to prove I'roperty 1.

Yemma 1-1 $\quad x \in \mathrm{D}_{y, \ldots, r} x \Leftrightarrow y \in \mathrm{D}_{x-, y} x$

This is clear from the symmetrie stmolntwe of the hamonized clictionary.

Lemma 1-2 If $X$ is a set (enery clement has a weight of 1$)$ lihen $\delta_{\mathrm{a}}\left(\mathrm{D}_{x \rightarrow y} X, y\right)=\delta_{\mathrm{a}}\left(X, \mathrm{D}_{y \rightarrow, x} y\right)$ lroof: $(|X|$ denotes the number of elements in $X)$

$$
\begin{aligned}
& \delta_{\mathrm{a}}\left(D_{x^{\prime} \rightarrow 1} X, y\right) \\
& =\left|\left\{x \mid x \in X \wedge y \in D_{x \cdots y} x\right\}\right| \\
& =\left|\left\{x \mid a \in X \wedge x \in \mathrm{D}_{y \rightarrow x} y\right\}\right| \\
& =\delta_{\mathrm{a}}\left(X, \mathrm{D}_{y-\rightarrow x} y\right) \quad \square
\end{aligned}
$$

As branches do not; overlap, $\mathrm{D}_{\mathrm{f} \rightarrow \mathrm{o}} \mathrm{f}$ is a set. From Iuemma 1.-2, the proof for Property 1 is given as follows:

$$
\begin{aligned}
& \delta_{\mathrm{a}}\left(\mathrm{D}_{\mathrm{e} \rightarrow \mathrm{j}} \mathrm{D}_{\mathrm{f} \rightarrow \mathrm{e}} \mathrm{f}, \mathrm{j}\right) \\
& =\delta_{\mathrm{a}}\left(\mathrm{D}_{\mathrm{f} \rightarrow \mathrm{e}} \mathrm{f}, \mathrm{D}_{\mathrm{e}-\mathrm{l}} \mathrm{j}\right) \\
& =\delta_{\mathrm{a}}\left(\mathrm{D}_{\mathrm{f} \rightarrow \mathrm{e}} \mathrm{f}, \mathrm{D}_{\mathrm{j} \rightarrow \mathrm{e}} \mathrm{f}\right) \\
& =\delta_{\mathrm{a}}\left(\mathrm{D}_{\mathrm{j} \rightarrow \mathrm{e}} \mathrm{f}, \mathrm{D}_{\mathrm{f} \rightarrow \mathrm{e}} \mathrm{f}\right)
\end{aligned}
$$

'The proof for the second equation is the same. 